\title{
An interview based approach to seeking user views in genitourinary medicine
}

\author{
D Evans, C Farquhar
}

Objectives: To assess user and potential user views on the appropriateness, nature and quality of genitourinary medicine (GUM) provision in Bristol, UK and to develop a model for ongoing user consultation by GUM providers and purchasers.

Design: This qualitative study was based on semi-structured interviews with service users, potential users, community informants and NHS professionals.

Participants: 76 current, past or potential users, 10 community informants and 11 NHS professionals were interviewed. African-Caribbean women and men, homeless men and women, lesbians and gay men, men and women living with HIV and women working in the sex industry were recruited to maximise the diversity of the sample.

Results: The interviews demonstrated that participants commented positively on many aspects of the service available. The research also identified a number of areas where the service could be improved. Many users emphasised their initial difficulty in finding out about the department and the need for greater publicity and outreach. Users reported coming to the clinic with high levels of anxiety and negative preconceptions about the GUM service. Specific issues were identified for different groups of users. There was a strongly expressed need from a number of women and African-Caribbean men for completely single sex clinics.

Conclusions: The research identified a number of issues of importance to service users that had not been identified in the department's own questionnaire surveys. The results support the premise that qualitative interviews can be successfully employed to access a diverse sample of users, and can offer insights significantly beyond those available from structured patient questionnaires.

(Genitourin Med 1996;72:223-226)

Keywords: genitourinary medicine; attenders; views

\section{Introduction}

Recent UK government policy has stressed the need for health services to be more responsive to the expressed needs and views of the public and service users. The White Paper Working for Patients, the 1990 NHS and Community Care Act and the NHS reforms which followed have all been grounded in a belief that the introduction of a NHS internal market gives users more choice and thus more voice in the provision of services. ${ }^{1}$ The Patient's Charter represents a related initiative to inform users of their rights, and empower them to demand appropriate standards of service. ${ }^{2}$ The NHS Quality initiative has further emphasised the need to consult users as part of clinical audit. ${ }^{3}$ There are a number of practical guides on methods to involve NHS users and the public in service planning and evaluation. ${ }^{4-9}$ Guidance to purchasers and providers of sexual health services has stressed the need to involve service users. ${ }^{10}$ Within the field of genitourinary medicine (GUM), there has been a growing recognition of the need to consult services users, and a number of initiatives have recently been reported. ${ }^{11-17} \mathrm{~A}$ national conference on quality and GUM services in 1994 heard a widely supported call for more research into user views in GUM. ${ }^{18}$

To date almost all published reports on user views in GUM have been based on the structured questionnaire survey approach. Although this research design has advantages in its ease of implementation, it also has many widely recognised limitations. An extensive literature demonstrates the limited and superficial nature of many structured questionnaire surveys in giving a real voice to health service users. ${ }^{19-23}$ In particular, structured questionnaires often do not allow or encourage users to identify or discuss the issues that are of real importance to them.

This research was designed to test an alternative approach, the qualitative semi-structured interview, to explore the experiences and views of GUM service users and potential users. The study aimed to assess user and potential user views on the appropriateness, nature and quality of GUM service provision, to make recommendations for future service development and to develop a model for ongoing consultation of service users by GUM providers and purchasers. The research focused on the Department of Genito-Urinary Medicine at the Bristol Royal Infirmary, an inner city clinic offering a range of sexually transmitted disease (STD) and HIV services with over 22000 attendances a year.

\section{Methods}

This study was based on semi-structured interviews with GUM service users, potential users, community informants and NHS professionals concerned with GUM services. The study did not seek to achieve a representative sample of users but to interview a range of respondents with a diversity of backgrounds, needs and views. It was decided to approach both ran-

Policy Studies,

University of

Southampton

D Evans

South Bank

ebruary 1996
} 
domly selected clinic users as well as people in specific targeted groups who might be expected to have particular service needs. Criteria for selecting target groups included epidemiological evidence of increased risk for STDs or HIV, identification as a target group in the local HIV and sexual health strategy and relative disadvantage in access to wider health services. The groups selected were African-Caribbean women and men, homeless men and women, lesbians and gay men, men and women living with HIV and women working in the sex industry. Potential users were recruited through voluntary organisations in contact with these groups. A small purposive sample of NHS professionals and community informants (mainly voluntary sector workers) was also identified for interview.

The semi-structured interview is a widely used form of social science enquiry. ${ }^{24} 25$ The interviewer begins with a set of open questions but is free to modify their order, give explanations or make other changes depending on what seems appropriate in the context of the particular interview. In this study the interviews were conducted by the authors with the female researcher interviewing women and the male researcher interviewing men. As the study involved NHS patients, local Research Ethics Committee approval was required and obtained. An advisory group was formed including a consultant in GUM, a senior health adviser, the purchaser's contracts manager, a health promotion manager and a voluntary sector representative.

The initial interview questions were drafted by the authors to be as open as possible to a range of user experiences and views (see Box 1). Subsequent questions included prompts about issues identified in previous research, suggested by clinic staff or raised by users in the pilot interviews. Issues raised in the prompted questions included the name of the clinic, the clinic environment, waiting times, mixed sex waiting and confidentiality.

Box 1: Initial Interview Questions:

* Overall, how does the clinic feel to you as a place to visit?

* What sort of things help to make it feel [like that]?

* Is there anything in particular you like or feel is good about the clinic?

* Is there anything you don't like or find difficult about the clinic?

* If you were in charge of this clinic, is there anything you would change?

The overall aim of analysis was to allow themes to emerge from the data, rather than to examine data within a predetermined framework. From repeated readings of the interview transcripts, a coding framework was developed which reflected the users' path through the department. Within each coding category, users' comments were grouped manually and the emerging themes identified and summarised. Final categories for the analysis are illustrated in Box 2.
Box 2: Interview Data Analysis Categories

1. Finding out about the service

2. Deciding to use the service

3. Making an appointment

4. Coming to the clinic

5. Clinic reception

6. Waiting to be seen

7. Seeing the doctor or nurse

8. Completing the visit

9. Major changes and service developments

\section{Results}

Seventy six current, past or potential users, 10 community informants and 11 NHS professionals were interviewed between September and December 1994. The sample included 4 African-Caribbean men, 7 African-Caribbean women, 6 lesbians, 16 gay men, $8 \mathrm{HIV}$ positive men, $7 \mathrm{HIV}$ positive women, 6 homeless women, 6 homeless men and 3 women working in the sex industry.

\section{Finding out about the Service}

Although a minority of respondents, particularly gay men, felt well informed about the department, many people emphasised their initial difficulty in finding out about it. As one man said "Finding the number of this place was a nightmare, because there's nothing in the book". Most felt there was a need for much greater publicity and outreach. A number of people highlighted the importance of general practitioners (GPs) as a source of referral, but GPs did not always appear to have communicated clear information and a positive message about the department.

\section{Deciding to use the Service}

The most common reason given for deciding to use the service was recommendation by friends, partners or a GP. One woman reported "It was a friend who said, 'The clinic's lovely, don't be worried about it. I've been down there, they're really nice,'-so that helped". Reasons given for using the department included wanting a service which was more anonymous, confidential, non-judgemental, caring, expert, convenient and quick than GP services. Several respondents reported that the HIV service was more friendly and accessible than the alternative local provider. Some users felt they had no choice but to use the department as it was the only local specialist STD service.

\section{Making an appointment}

Although some difficulties were reported in getting through on the telephone to make appointments, most users were positive about the way their enquiry was dealt with when they did get through. Some respondents had no difficulty in getting convenient or quick appointments, while others expressed dissatisfaction with the limited evening opening, the lack of "drop-in" sessions and access to specific doctors. A number of women had assumed (wrongly) that "women only" sessions would 
be staffed only by female staff, and were unclear how to choose an appointment with a woman doctor.

\section{Coming to the Clinic}

A large number of respondents found entering the clinic to be extremely anxiety-provoking, especially the first time. One man commented "I think (the entrance) is like a threat, it was horrible. Walking into here, everybody looking at you and thinking what diseases I had and, 'I hope I don't get it'." Most users' concerns focused on how they would be treated, and who might recognise them. Some fears were more commonly reported by specific groups. Women working in the sex industry and AfricanCaribbean men were particularly concerned about being recognised in the waiting area and, along with lesbians, disliked the mixed sex entrance. Some women reported they found entering the clinic difficult as it raised strong emotions about their reason for attending (such as anger at a partner's infidelity). Some men expressed fears and preconceptions about potentially painful treatments.

\section{Clinic reception}

The way in which users were greeted at reception often set the tone for how they experienced the clinic as a whole. Most respondents were very positive about their contact with receptionists, and this helped to reduce the anxiety they arrived with. One young woman reported "whatever they were trying to do to make me relaxed worked". However, some respondents, particularly women, expressed discomfort about being asked for information at reception, often because of fears about confidentiality and privacy. Concerns about being overheard were sometimes exacerbated by the presence of the opposite sex, and many women and some men voiced a strong preference for separate male and female reception areas.

\section{Waiting to be seen}

Waiting times were a source of complaint for many users, particularly women. Although some were resigned to long waits, others felt that the system could be improved (for example, by keeping users better informed of delays). Suggestions for improving the waiting environment including broadening the range of images portrayed (for example, to include Black, lesbian and gay and youth images) and improving amenities. However, the issue many respondents felt most strongly about was the mixed sex nature of the waiting area. The great majority of women were strongly in favour of a woman-only waiting area to help them feel "safe", and many wanted a separate entrance and reception desk. Some felt that ideally there should be three waiting areas: one mixed, one male and one female. Men were more divided in their views. Some expressed no preference, some (particularly gay men) welcomed the mixed sex area, and a small number (including all the African-Caribbean men), preferred a men-only space. As one man said "You should never have mixed waiting, it's too public".

\section{Seeing the doctor or nurse}

The great majority of users made positive comments about the attitudes of the doctors and nurses in the clinic, using terms such as "friendly", "courteous", "open", and "reassuring". The key to many users' experience was the extent to which they felt they were treated with respect and in a "non-judgemental" manner. For example, whilst some lesbian and gay users reported that staff made unwarranted assumptions about their sexuality, others expressed relief when staff were non-judgemental. A number of users were relieved not to be judged about their sexual behaviour (for example, having more than one partner and having sex at a young age). For women in particular this contributed to them not feeling embarrassed, irresponsible or dirty. One woman said "[the doctor] wasn't in any way censoring or critical of what I was doing and why $I$ was doing it and as I left she actually kind of winked at me and said 'Have a nice time tonight', and I thought, 'Oh, this is wonderful'. I don't think I will ever forget her for that . . ."

\section{Completing the visit}

Some users had seen a health adviser, and of these, the great majority reported very positive experiences of the information, care and support they received. Some women expressed anxiety about walking out the door of the clinic. Although not as stressful as entering, some would have liked more support or time before leaving.

\section{Major changes and service developments}

Many HIV positive respondents expressed a strong desire for an integrated in-patient and out-patient HIV unit. There were mixed views over the desirability of greater integration of HIV and STD services, and the desirability of a more integrated sexual health service encompassing contraception services.

\section{Discussion}

The results demonstrate that the great majority of respondents valued many aspects of the service they received. These users appreciated the non-judgemental attitudes, commitment and care demonstrated by clinic staff. However, the research also identified a number of areas where the service could be improved. Several issues (such as the difficulty first time users had in finding the service, the fears and preconceptions experienced in coming to the service, staff attitudes to sexuality) had not previously been identified in the department's own questionnaire surveys of users. Other issues which had been covered in previous surveys (such as single sex clinics) had not been examined in depth, nor had the diversity of user views been explored. The use of community based interviews led to the identification of the needs of specific groups (for example, lesbians, homeless women and men) which had not been addressed in previous surveys. The results thus support the premise of this research: in-depth qualitative interviews can offer insights into user views 
and experiences in GUM services significantly beyond those available from structured patient questionnaires.

The respondents interviewed in Bristol were not randomly selected, and cannot be assumed to be representative of Bristol users more generally, nor of users of GUM services in other localities. However, the issues raised here are important to at least some users, and offer rich data which GUM providers and other researchers can build upon. This study was successful in recruiting diverse users with particular needs (such as lesbians, AfricanCaribbean women and men) whose views have not often been addressed in GUM research. The validity of these results is, moreover, likely to be high. Because open questions were used, and coding and analysis was based on common themes emerging from the data, the results are more likely to reflect the reality of user views than results from structured questionnaires with predetermined closed questions.

Although some of the user experiences and views identified in this research are likely to be specific to the Bristol context, other concerns are probably shared by users in other localities. Given the stigma associated with STDs and the diversity of clinic names, the difficulty of first time users in Bristol in finding out about the services may well be a more widespread problem. The anxiety experienced by Bristol users in approaching the clinic is echoed in unpublished audit reports obtained by the authors from other GUM departments that have examined such issues, and is equally likely to be widespread. The desire of some users to have a choice of single sex clinics has been reported in several unpublished clinic surveys. Women, African-Caribbean men and others may well experience difficulties in exercising such a choice in a number of localities.

One of the objectives of this study was to develop a model for ongoing consultation of GUM service users. The model developed through this project proposes that both traditional survey based methods and qualitative methods be drawn upon to develop appropriate user consultation. A set of flexible guidelines have been produced which suggest a step by step planning process for seeking user views in GUM. ${ }^{26}$ The model recognises the resource constraints of providers and the difficulty of conducting the depth of qualitative research carried out in this study. Nevertheless, there are aspects of the qualitative method which might improve current practice in GUM user consultation. A limited number of semi-structured interviews could be used to produce a validated interview schedule for a structured questionnaire survey, thus ensuring that the survey was based on user experiences and perceptions rather than those of professionals.

We thank all the users, GUM providers, purchasers and voluntary sector colleagues in Bristol whose cooperation was vital for this research. The research was funded by Bristol and District Health Authority.

1 Department of Health. Working for Patients. London, 1989 2 Department of Health. The Patient's Charter (2nd Edition). London, 1995.

3 NHS Management Executive. The Quality fourney: $A$ Guide to Total Quality Management in the NHS. Leeds, 1992.

4 NHS Management Executive. Local Voices. London, 1992. 5 National Association of Health Authorities and Trusts. Listening to Local Voices. Birmingham, NAHAT, 1993.

McIver S. An Introduction to Obtaining the Views of Users of Health Services. London, King's Fund Centre, 1991.

7 McIver S. Obtaining the Views of Outpatients. London, King's Fund Centre, 1991

8 McIver S. Obtaining the Views of Users of Primary and Community Health Care Services. London, King's Fund Centre, 1993.

9 McIver S. Obtaining the Views of Black Users of Health Services. London, King's Fund Centre, 1994.

10 Department of Health. HIVIAIDS and Sexual Health Key Area Handbook. London, 1993.

11 Boag F. A women's only session in a genitourinary medicine clinic. In: Pilaye J ed. Sexual Health Promotion medicine clinic. In: Pilaye J ed. Sexual Health Promotion Education Authority, 1994.

12 Rogstad K. Patients' assessment of and suggestions for genitourinary medicine service. Int $\mathcal{F}$ of STD/AIDS 1991 2:440-1.

13 Monteiro E. An audit of patients' views in Yorkshire genitourinary medicine clinics. Int $f$ STD/AIDS 1995;6: 217-22.

14 Munday P. Genitourinary medicine services: consumers' views. Genitourin Med 1990;66:108-11.

15 Queen $\mathrm{H}$, Ward H, Smith C, Woodroffe C. Women's health: potential for better coordination of services. Genitourin Med 1991;67:215-9.

16 Whittaker D. "In the room"-Invisible Work and Hidden Experiences of Women Nurses and Women Patients in a Genito-Urinary Medicine Clinic: An Exploratory Study. Genito-Urinary Medicine Clinic: An Exploratory Study.
London, James Pringle House, Middlesex Hospital, 1993.

17 Kumari V. The Camberwell Study of Black Clinic Attenders and HIV. London, King's Health Care, 1992.

18 South East Thames Regional Health Authority \& King's Healthcare. Buying quality in GUM and HIV-who cares? Report of proceedings of a conference held on 9 March 1994 at Guy's Hospital, London 1994.

19 Blaxter M. Consumers $\&$ Research in the NHS: An RED contribution to consumer involvement in the NHS. London, Department of Health, 1995.

20 Coote A. Public Participation in Decisions About Health Care. Critical Public Health 1993;4:36-49.

21 Shackley P, Ryan M. What is the Role of the Consumer in Health Care? foumal of Social Policy 1994;23:517-41.

22 Williams B. Patient Satisfaction: A Valid Concept? Soc Sci Med 1994;38:509-16.

23 Woodward N. Public Involvement in Health Care Purchasing: An Investigation of Process. MSc Dissertation, University of Southampton, 1994.

24 Robson C. Real World Research. Oxford, Blackwell, 1993.

25 Holstein J, Gubrium J. The Active Interview. Qualitative Research Methods Vol 37. London, Sage, 1995.

26 Evans D, Farquhar C. Guidelines for Seeking User Views in Genito-Urinary Medicine. Southampton, Institute for Health Policy Studies, 1995. 